\title{
Epidemiological assessment of the risk of canine mast cell tumours based on the Kiupel two-grade malignancy classification
}

\author{
Anna Śmiech ${ }^{1 *} \mathbb{D}$, Brygida Ślaska² ${ }^{2}$ Wojciech Łopuszyński ${ }^{1}$, Agnieszka Jasik ${ }^{3}$, Diana Bochyńska ${ }^{4}$ and Roman Dąb \\ rowski ${ }^{5}$
}

\begin{abstract}
Background: The degree of differentiation of mast cell tumours (MCTs) is the most important feature and reflects the morphological characteristics and metastatic potential of the tumour and its likely response to treatment and the prognosis. The aim of this study was to epidemiologically analyse the risk of MCT development in dogs according to breed, age, sex, size and anatomical location of the tumour using the Kiupel grading system. The analysis involved 492 dogs selected based on a histopathological assessment of 2763 canine skin tumours. A logistic regression analysis was performed to determine the odds ratios (ORs) with 95\% confidence intervals.

Results: Mast cell tumours accounted for $17.8 \%$ of all diagnosed canine skin tumours. The highest risk of high-grade MCTs was noted in the Shar-Pei (OR 28.18, $\mathrm{P}<0.001)$ and Weimaraner (OR 6.45, $\mathrm{P}=0.023)$. The highest risk of lowgrade MCTs was determined in the Boxer (OR 6.72, $\mathrm{P}<0.001)$, and Pug (OR 6.13, $\mathrm{P}=0.027)$. The scrotum (OR 31.72, $\mathrm{P}<0.001)$, inguinal area $(\mathrm{OR} 17.69, \mathrm{P}<0.001)$ and axilla $(\mathrm{OR} 6.30, \mathrm{P}<0.001)$ had the highest risk of high-grade MCTs. The risk of high-grade MCTs increased with age and peaked in the oldest dogs, aged 11-16 years (OR 9.55, $\mathrm{P}<0.001)$. A higher risk of low-grade tumours was noted in younger dogs (aged $4-6$ years) $(\mathrm{OR} 8.54, \mathrm{P}<0.001)$ and females (OR $1.43, P=0.001)$. Statistical analysis further revealed a higher risk of both low (OR 3.47, $P<0.001)$ and high-grade MCTs (OR 1.71, $\mathrm{P}=0.006)$ in medium-sized dogs.
\end{abstract}

Conclusions: This study demonstrated relationships between Kiupel grading system and phenotypic traits, age and location of canine MCTs confirming the complex biological nature of this tumour.

Keywords: Dog, Epidemiological study, Kiupel grade, Mast cell tumours

\section{Background}

Mast cell tumours (MCTs) are characterised by a varied clinical course. They take the form of small, demarcated, single or multiple tumours, they may infiltrate the surrounding tissues and metastasise to lymph nodes and internal organ [1-4]. Although many investigations have focused on identifying the factors determining the probable course of the disease, the degree of histological

\footnotetext{
*Correspondence: anna.smiech@up.lublin.pl

${ }^{1}$ Sub-Department of Pathomorphology and Forensic Veterinary

Medicine, Department and Clinic of Internal Medicine, Faculty

of Veterinary Medicine, University of Life Science Lublin, Akademicka 13

St., 20-950 Lublin, Poland

Full list of author information is available at the end of the article
}

differentiation is still the most important predictor [5$10]$ and determines not only the morphological characteristics and metastatic potential of a tumour but also its response to treatment and the prognosis [3, 11, 12]. Before 2011, the most widely used malignancy differentiation system was the three-grade Patnaik scale, which distinguished well, moderately, and poorly differentiated MCTs, referred to as GI, GII, and GIII [13]. Due to the heterogeneous character of moderately differentiated tumours and their unpredictable clinical course, Kiupel et al. [14] proposed a new 2-grade malignancy classification, i.e., low-grade and high-grade, based on the morphology of the cells' nucleus and the number of mitotic division figures. MCTs with a high malignancy grade are 
transformations involving at least 7 mitotic division figures, three multinucleated cells, three cells with bizarre nuclei per 10 high-power fields, and $10 \%$ of cells with karyomegaly. All other tumours that do not meet these criteria are classified as low-grade (Additional file 1). In accordance with the new classification system, highgrade tumours are characterised by a more aggressive disease course, a tendency to relapse and metastasise, and a shorter patient survival time. The median survival time is approximately 4 months in the case of high-grade MCTs and 2 years for low-grade MCTs [14]. Epidemiological investigations conducted so far have mainly focused on assessing the risk of MCT development in specific dog breeds in a specific geographical region. The risk of this type of tumour in relation to the dog's age, sex, and body weight and in castrated or sterilised dogs has been demonstrated [15-24]. Only one report has presented an epidemiological analysis of the incidence of MCTs based on the two-grade malignancy [25]. Prognosis is controversial and depends on the location of the MCTs. MCTs can develop in every part of the body, although the most frequent locations include the torso (50-60\%), limbs (25-40\%), and head and neck (10\%) [4]. In turn, MCT locations with a poorer prognosis include the perineal area, perineal-perianal area, and mucocutaneous junctions $[1,2,4,12]$. Some authors claim that a worse prognosis is often associated with the development of poorly differentiated MCTs, whereas other researchers relate it to difficulties in performing surgery [26, 27]. Therefore, a retrospective analysis of the risk of development of low- and high-grade MCTs could be extremely helpful for prognosis. There are no epidemiological studies in the veterinary literature based on the Kiupel twograde classification of malignancy, which is the basic prognostic factor determining the course of the disease.

The aim of this study was to conduct an epidemiological analysis of the risk of MCT development in dogs in relation to other skin tumours and to use the data in the prognosis of the neoplastic disease. Relationships between the dog's breed, age, sex, size, anatomical location of the tumour, and degree of MCT malignancy specified by the Kiupel two-grade malignancy scale were assessed.

\section{Methods}

The analysis involved 492 dogs of 77 breeds and crossbreed dogs diagnosed with skin MCTs, which were selected based on a histopathological assessment of 2763 canine skin tumour cases diagnosed at the SubDepartment of Pathomorphology and Forensic Veterinary Medicine, University of Life Sciences in Lublin, Poland from 2003 to 2016. Due to the small number of dogs, 51 breeds represented by 31 individuals with
MCTs and 433 dogs with skin tumours were classified into one group, i.e., other breeds. The analysis was conducted in 26 breeds, crossbreed dogs, and the group of other breeds. The tumour samples for histopathological examination originated from dogs treated with surgical resection of the skin tumour, which was performed at the Veterinary Clinic, University of Life Sciences in Lublin and at private veterinary clinics in Poland. Slides for microscopic evaluation were routinely stained with haematoxylin and eosin as well as toluidine blue. The histopathological analysis of the MCTs was performed according to the WHO classification based on the two-grade malignancy scale of Kiupel et al. [14, 28]. Tumours sampled before 2011 and evaluated according to the Patnaik scale were reclassified by three pathologists. Clinical data on the dogs' breed, age, sex, and tumour location were derived from records delivered to the Department, together with tissue submitted for histopathological examination. Only dogs with a complete set of data were qualified for inclusion in the study; hence, 78 cases were excluded from the analyses. The analyses were performed on tumours diagnosed in an individual for the first time.

Dogs were divided into three groups according to size: small (S), estimated wither height (EWH) $30-45 \mathrm{~cm}$, medium (M, EWH 45-60 cm), and large (L, EWH $>60 \mathrm{~cm}$ ) [29]. The crossbreed dogs were excluded from the body-size assessment. Additionally, four age groups were distinguished: (1) dogs aged 0-3 years, (2) 4-6 years, (3) 7-10 years, and (4) 11-16 years. Eleven tumour locations were distinguished: (1) head, (2) neck, (3) torso, (4) thoracic limb, (5) axilla, (6) pelvic limb, (7) inguinal area, (8) perineum (9) scrotum, (10) anus, and (11) tail.

The risk of MCT development according to breed, sex, size, location, and age range was determined based on the odds ratio (OR). The control (reference) group comprised dogs with skin tumours diagnosed at the Sub-Department of Pathomorphology and Forensic Veterinary Medicine, University of Life Sciences in Lublin during the same period, i.e., from 2003 to 2016. A logistic regression analysis was performed to determine the ORs with 95\% confidence intervals (CIs). For dogs assigned to a breed, ORs were calculated by comparing the MCT incidence in the analysed breed with that in the other breeds diagnosed with skin tumours (control group). Analogous calculations were conducted for tumour location. For the calculations of ORs relative to age, the dogs were divided into four age groups, and the younger animals (up to 3 years of age) were regarded as the basal group. Small dogs and males were the basal groups in the determination of ORs for size and sex, respectively. The analysis was conducted using the Statistica 9.1 program 
(StatSoft ${ }^{\circledR}$, Cracow Poland). Values of $\mathrm{P}<0.05$ were considered significant.

\section{Results}

The 492 cases of MCTs accounted for $17.8 \%$ of all skin tumours. Among the skin tumours, $19.6 \%$ sebaceous and sweat gland tumours, $15.9 \%$ histiocytic tumours, $10.9 \%$ epidermal tumours, $10.8 \%$ follicular tumours and $5.0 \%$ melanocytic tumours were identified. In turn, mesenchymal neoplasms and other tumours accounted for $20.0 \%$ of the examined skin tumours. According to the two-grade classification of Kiupel et al. [14], low-grade tumours were dominant, representing $75.8 \%$; the other cases were classified as high-grade tumours (Table 1). The greatest proportion of MCTs was detected in the Boxer breed (19.1\%), of which $96.8 \%$ were classified as low grade. Furthermore, a high percentage of MCTs were noted in Labrador Retrievers, American Staffordshire Terriers, Golden Retrievers, French Bulldogs, Dachshunds, and Shar-Peis (ranging from 2.6 to 9.9\%) (Table 1). In terms of location, the greatest numbers of MCTs were noted on the torso (36.9\%); they were dominated by low-grade tumours $(80.2 \%)$. In turn, the highest frequency of highgrade tumours $(73.3 \%)$ was noted in the inguinal region

Table 1 Frequency of MCTs in various breeds of dogs according to the Kiupel grading system

\begin{tabular}{|c|c|c|c|c|c|c|c|c|}
\hline \multirow[t]{3}{*}{ Breed } & \multirow{2}{*}{\multicolumn{2}{|c|}{ All MCTs }} & \multicolumn{4}{|c|}{ Kiupel grade } & \multirow{2}{*}{\multicolumn{2}{|c|}{ Control group $^{d}$}} \\
\hline & & & \multicolumn{2}{|l|}{ Low } & \multicolumn{2}{|c|}{ High } & & \\
\hline & $\mathbf{N}$ & $\%$ & $\mathrm{~N}$ & $\%^{\mathrm{a}}$ & $\mathrm{N}$ & $\%^{\mathbf{b}}$ & $\mathbf{N}$ & $\%$ \\
\hline Boxer & 94 & 19.1 & 91 & 96.8 & 3 & 3.1 & 104 & 4.5 \\
\hline Labrador & 49 & 9.9 & 40 & 81.6 & 9 & 18.3 & 96 & 4.2 \\
\hline American Staffordshire Terrier & 30 & 6.1 & 22 & 73.3 & 8 & 26.6 & 53 & 2.3 \\
\hline Golden Retriever & 19 & 3.8 & 16 & 84.2 & 3 & 15.7 & 64 & 2.8 \\
\hline French Bulldog & 15 & 3.0 & 11 & 73.3 & 4 & 26.6 & 34 & 1.5 \\
\hline Dachshund & 14 & 2.8 & 5 & 35.7 & 9 & 64.2 & 93 & 4.0 \\
\hline Shar-Pei & 13 & 2.6 & 1 & 7.6 & 12 & 92.3 & 9 & 0.4 \\
\hline Bernese Mountain Dog & 11 & 2.2 & 7 & 63.6 & 4 & 36.3 & 39 & 1.7 \\
\hline German Shepherd & 9 & 1.8 & 6 & 66.6 & 3 & 33.3 & 211 & 9.2 \\
\hline Miniature Schnauzer & 7 & 1.4 & 6 & 85.7 & 1 & 14.2 & 52 & 2.2 \\
\hline Irish Setter & 5 & 1.0 & 5 & 100.0 & 0 & 0.0 & 23 & 1.0 \\
\hline Standard Schnauzer & 5 & 1.0 & 3 & 60.0 & 2 & 40.0 & 29 & 1.2 \\
\hline Cocker Spaniel & 4 & 0.8 & 4 & 100.0 & 0 & 0.0 & 91 & 4.0 \\
\hline Doberman & 4 & 0.8 & 3 & 75.0 & 1 & 25.0 & 40 & 1.7 \\
\hline Maltese & 4 & 0.8 & 4 & 100.0 & 0 & 0.0 & 9 & 0.4 \\
\hline Bull Terrier & 3 & 0.6 & 3 & 100.0 & 0 & 0.0 & 15 & 0.6 \\
\hline Pug & 3 & 0.6 & 3 & 100.0 & 0 & 0.0 & 3 & 0.1 \\
\hline Polish Tatra Sheepdog & 3 & 0.6 & 2 & 66.6 & 1 & 33.3 & 7 & 0.3 \\
\hline Siberian Husky & 3 & 0.6 & 3 & 100.0 & 0 & 0.0 & 33 & 1.4 \\
\hline Weimaraner & 3 & 0.6 & 1 & 33.3 & 2 & 66.6 & 6 & 0.2 \\
\hline Saint Bernard & 2 & 0.4 & 2 & 100.0 & 0 & 0.0 & 14 & 0.6 \\
\hline Jack Russell Terrier & 2 & 0.4 & 1 & 50.0 & 1 & 50.0 & 7 & 0.3 \\
\hline Caucasian Shepherd & 2 & 0.4 & 2 & 100.0 & 0 & 0.0 & 7 & 0.3 \\
\hline Miniature Poodle & 2 & 0.4 & 1 & 50.0 & 1 & 50.0 & 4 & 0.1 \\
\hline Standard Poodle & 2 & 0.4 & 2 & 100.0 & 0 & 0.0 & 22 & 0.9 \\
\hline Yorkshire Terrier & 2 & 0.4 & 2 & 100.0 & 0 & 0.0 & 81 & 3.5 \\
\hline Other breeds & 31 & 6.3 & 24 & 77.4 & 7 & 22.5 & 433 & 19.0 \\
\hline Crossbreed & 151 & 30.6 & 103 & 68.2 & 48 & 31.7 & 692 & 30.4 \\
\hline Total & 492 & $17.8^{c}$ & 373 & 75.8 & 119 & 24.1 & 2271 & 82.2 \\
\hline
\end{tabular}

a Percentage of dogs with low-grade MCTs within a given breed of dog with MCTs

b Percentage of dogs with high-grade MCTs within a given breed of dog with MCTs

c Percentage of dogs with MCTs among all tested dogs

${ }^{d}$ Total number of dogs with other skin tumours within a given breed 
(Table 2). Data presenting the frequency of MCTs in relation to the dog's sex, size, and the four age groups in the analysed dog population are shown in Table 3. The highest risk of MCT development, compared with that of other skin tumours, was detected in five breeds: Shar-Pei, Boxer, American Staffordshire Terrier, Labrador Retriever, and French Bulldog. In turn, the lowest incidence was found in Cocker Spaniel, German Shepherd, and Yorkshire Terrier (Table 4). The statistical analysis based on the Kiupel two-grade malignancy scale revealed the highest risk of high-grade MCT development in three breeds: Shar-Pei, Weimaraner and American Staffordshire Terrier (Table 4). The highest risk of low-grade MCTs was observed in five breeds: Boxer, Pug, Labrador Retriever, American Staffordshire Terrier and French Bulldog (Table 4).

The scrotum was characterised by the highest risk of MCT development of all the skin tumour locations (Table 5). This region exhibited a substantially greater risk of high-grade tumour development (Fig. 1), although the OR indicator for low-grade MCTs was also high (Table 5). Other localities with high OR values included the inguinal area, axilla and torso (Table 5). Higher OR values were determined for high-grade tumours in the inguinal area and axilla. In turn, the torso was found to be the region with the highest risk of low-grade tumour development (Table 5).

A higher risk of MCT development was noted in females than in males, including a higher risk of lowgrade MCTs (Table 6). There was an increased risk of
MCT development in older dogs aged 4-6 years and 7-10 years compared with that in the youngest dog group (less than 3 years old) (Table 6). Similar correlations were observed for high-grade tumours, but the highest OR value was noted in the oldest dog group (aged 11-16 years). The highest risk of low-grade tumours was reported for younger dogs aged 4-6 years compared with the youngest group (less than 3 years old) (Table 6). The statistical analysis based on size revealed a higher risk of low- and high-grade MCTs in the medium-sized breeds than in the small ones, whereas no significant correlations were found for the large breeds (Table 6).

\section{Discussion}

Mast cell tumours accounted for $17.8 \%$ of all the examined skin tumours which corresponds to the frequency found in other studies $(7-21 \%)[4,21,30]$. The results of this study indicated an increased risk of MCT development in five breeds: Shar-Pei, American Staffordshire Terrier, Labrador Retriever, French Bulldog, and Boxer (Table 4). The results most similar to those found in our study were obtained in investigations conducted in the UK, where the highest risk was predicted for Boxers, Labrador Retrievers, Golden Retrievers, and Staffordshire Bull Terriers [22]. Other studies conducted in the UK demonstrated an increased risk of MCT development in Weimaraners as well [20]. Our study confirmed the increased rate of high-grade MCT development in this breed. Epidemiological studies conducted in the USA showed that breeds such as Boxers, Vizslas, Rhodesian

Table 2 Frequency of MCT grades by tumour location

\begin{tabular}{|c|c|c|c|c|c|c|c|c|}
\hline \multirow[t]{3}{*}{ Location } & \multirow{2}{*}{\multicolumn{2}{|c|}{ All MCTs }} & \multicolumn{4}{|c|}{ Kiupel grade } & \multirow{2}{*}{\multicolumn{2}{|c|}{ Control group ${ }^{c}$}} \\
\hline & & & \multicolumn{2}{|l|}{ Low } & \multicolumn{2}{|c|}{ High } & & \\
\hline & $\mathrm{N}$ & $\%$ & $\mathbf{N}$ & $\%^{a}$ & $\mathrm{~N}$ & $\%^{\mathbf{b}}$ & $\mathbf{N}$ & $\%$ \\
\hline Torso & 182 & 36.9 & 146 & 80.2 & 36 & 19.7 & 620 & 27.3 \\
\hline Pelvic limb & 93 & 18.9 & 80 & 86.0 & 13 & 13.9 & 331 & 14.5 \\
\hline Head & 55 & 11.1 & 45 & 81.8 & 10 & 18.1 & 506 & 22.2 \\
\hline Thoracic limb & 55 & 11.1 & 47 & 85.4 & 8 & 14.5 & 298 & 13.1 \\
\hline Axilla & 22 & 4.4 & 8 & 36.3 & 14 & 63.6 & 47 & 2.0 \\
\hline Neck & 21 & 4.2 & 16 & 76.1 & 5 & 23.8 & 109 & 4.8 \\
\hline Scrotum & 21 & 4.2 & 9 & 42.8 & 12 & 57.1 & 8 & 0.3 \\
\hline Inguinal area & 15 & 3.0 & 4 & 26.6 & 11 & 73.3 & 13 & 0.5 \\
\hline Perineum & 12 & 2.4 & 5 & 41.6 & 7 & 58.3 & 30 & 1.3 \\
\hline Tail & 10 & 2.0 & 10 & 100.0 & 0 & 0.0 & 79 & 3.4 \\
\hline Anus & 6 & 1.2 & 3 & 50.0 & 3 & 50.0 & 230 & 10.1 \\
\hline Total & 492 & 100.0 & 373 & 75.8 & 119 & 24.1 & 2271 & 100.0 \\
\hline
\end{tabular}

a Percentage of low-grade MCTs in a given location

b Percentage of high-grade MCTs in a given location

c Total number of dogs with other skin tumours in a given location 
Table 3 Frequency of MCT grade by age, size and sex

\begin{tabular}{|c|c|c|c|c|}
\hline \multirow[t]{2}{*}{ Variable } & \multirow[t]{2}{*}{ All MCTs } & \multicolumn{2}{|c|}{ Kiupel grade } & \multirow[t]{2}{*}{ Control group ${ }^{b}$} \\
\hline & & Low & High & \\
\hline \multicolumn{5}{|l|}{ Age (years) } \\
\hline \multirow[t]{2}{*}{$0-3$} & 15 & 11 & 4 & 398 \\
\hline & $3.0 \%$ & $2.9 \%$ & $3.3 \%$ & $17.5 \%$ \\
\hline \multirow[t]{2}{*}{$4-6$} & 127 & 110 & 17 & 466 \\
\hline & $25.8 \%$ & $29.4 \%$ & $14.2 \%$ & $20.5 \%$ \\
\hline \multirow[t]{2}{*}{$7-10$} & 262 & 210 & 52 & 928 \\
\hline & $53.2 \%$ & $56.3 \%$ & $43.7 \%$ & $40.8 \%$ \\
\hline \multirow[t]{2}{*}{$11-16$} & 88 & 42 & 46 & 479 \\
\hline & $17.8 \%$ & $11.2 \%$ & $38.6 \%$ & $21.0 \%$ \\
\hline$M \pm S D$ & $8.09 \pm 2.72$ & $7.64 \pm 2.42$ & $9.52 \pm 3.10$ & $7.44 \pm 3.73$ \\
\hline \multicolumn{5}{|c|}{ ( } \\
\hline \multirow[t]{2}{*}{ Small } & 65 & 46 & 19 & 474 \\
\hline & $19.0 \%$ & $17.0 \%$ & $26.7 \%$ & $30.0 \%$ \\
\hline \multirow[t]{2}{*}{ Medium } & 207 & 172 & 35 & 510 \\
\hline & $60.7 \%$ & $63.7 \%$ & $49.3 \%$ & $32.3 \%$ \\
\hline \multirow[t]{2}{*}{ Large } & 69 & 52 & 17 & 594 \\
\hline & $20.2 \%$ & $19.2 \%$ & $23.9 \%$ & $37.6 \%$ \\
\hline \multicolumn{5}{|l|}{ Sex } \\
\hline \multirow[t]{2}{*}{ Male } & 274 & 205 & 69 & 1444 \\
\hline & $55.6 \%$ & $54.9 \%$ & $57.9 \%$ & $63.5 \%$ \\
\hline \multirow[t]{2}{*}{ Female } & 218 & 168 & 50 & 827 \\
\hline & $44.3 \%$ & $45.0 \%$ & $42.0 \%$ & $36.4 \%$ \\
\hline Total & 492 & 373 & 119 & 2271 \\
\hline
\end{tabular}

$M$ mean, $S D$ standard deviation

a The analysis did not take into account crossbreed dogs, whose size was not recognized

b Total number of dogs with other skin tumours of a given age, size and sex

Ridgebacks, Boston Terriers, Weimaraners, and Chinese Shar-Peis were more susceptible to MCTs [21]. Differences in MCT incidence among different breeds is associated with the geographical area and the selection of the control population, which in some investigations comprised insured populations [18, 22], dogs registered with kennel associations (Kennel Club registrations) [19, 22], or hospitalised dogs $[21,22]$. The control group in our study comprised dogs with skin tumours. Regardless of the geographic area and the control population, all epidemiological studies have revealed an increased risk of MCT development in Boxers [19-23]. The present study confirmed these observations. Moreover, the statistical analysis revealed an increased incidence of MCTs in American Staffordshire Terriers and French Bulldogs. There is a hypothesis that Boxers, American Staffordshire Terriers and French Bulldogs may be related and have a common ancestor in their phylogenetic development [31]. The present study demonstrated a high risk of MCTs in the Shar-Pei simultaneously with an increased risk of high-grade MCTs (Table 4). Our results confirm previous reports of greater susceptibility of this breed to MCTs characterised by a higher malignancy grade and a worse clinical course [32-34]. As shown previously, the Labrador Retriever breed is at increased risk of this type of tumour [22, 23]. This finding was also confirmed in the present study, which additionally revealed a higher risk of low-grade MCTs (Table 3). Recent investigations suggest that low levels of $25(\mathrm{OH}) \mathrm{D} 3$ might be a risk factor for MCTs in this breed [35]. Available published data show that Boxers and Pugs are characterised by higher susceptibility to low-grade MCTs [25, 32, 34, 36, 37]. Our epidemiological analysis confirmed these observations and demonstrated an increased risk of low-grade MCTs in French Bulldog and American Staffordshire Terrier. In the latter breed, a higher risk of high-grade MCTs was revealed as well (Table 3), which may be related to the phylogenetic origin. The American Staffordshire Terrier is a cross between the Bulldog and the Terrier. In Bulldogs, a higher risk of low-grade MTC occurrence has been observed [25]. Although there are no reports on the occurrence of high-grade MCT in Terriers, genetic factors should be considered. Other mechanisms in addition to genetic factors probably play an important role and may be responsible for the biological behaviour of tumours in a given breed. Investigations of mitochondrial DNA conducted in recent years have demonstrated somatic mutations in the mitochondrial DNA D-loop in MCTs, which may also be associated with neoplastic transformation [38]. The present epidemiological analysis also showed a reduced risk of MCT development in three breeds, i.e., German Shepherd, Yorkshire Terrier, and Cocker Spaniel (Table 3), which is consistent with previous studies [20-22].

The veterinary literature contains many discrepancies regarding the risk of development of MCTs in females and males. Most reports confirm the absence of a correlation between the animal's sex and MCT development $[20,33]$. The present results showed a higher risk of MCT development in females (OR 1.38, $\mathrm{P}=0.001$ ), with a concurrent tendency towards low-grade tumours (OR $1.43, \mathrm{P}=0.001$ ) (Table 5). A study conducted by Mochizuki et al. [25] reported a greater number of high-grade tumours in males and non-castrated dogs. In turn, some published data suggest that castration and sterilisation increase the MCT risk [23, 24, 39]. These data imply that the role of sex hormones in MCT development is not fully understood, and further investigations are required to elucidate this issue.

The present study showed correlations between the anatomical location of the tumour and the presence of MCTs. The statistical analysis demonstrated that the scrotum had the greatest risk of MCT development of all 
Table 4 Odds ratios (ORs) and 95\% confidence intervals (Cls) for particular grades of MCTs in various breeds of dogs

\begin{tabular}{|c|c|c|c|c|c|c|}
\hline \multirow[t]{3}{*}{ Breed } & \multirow{2}{*}{\multicolumn{2}{|c|}{ All MCTs }} & \multicolumn{4}{|l|}{ Kiupel grade } \\
\hline & & & \multicolumn{2}{|l|}{ Low } & \multicolumn{2}{|l|}{ High } \\
\hline & OR $(95 \% \mathrm{Cl})$ & $\mathbf{P}$ & OR $(95 \% \mathrm{Cl})$ & $P$ & OR $(95 \% \mathrm{Cl})$ & $P$ \\
\hline American Staffordshire Terrier & $2.71(1.71-4.3)$ & $<0.001$ & $2.62(1.57-4.36)$ & $<0.001$ & $3.01(1.40-6.49)$ & 0.005 \\
\hline Bernese Mountain Dog & $1.30(0.66-2.57)$ & 0.435 & $1.09(0.48-2.46)$ & 0.827 & $1.99(0.69-5.66)$ & 0.197 \\
\hline Boxer & $4.92(3.65-6.63)$ & $<0.001$ & $6.72(4.94-9.14)$ & $<0.001$ & $0.53(0.16-1.72)$ & 0.297 \\
\hline Bull Terrier & $0.92(0.26-3.19)$ & 0.899 & $1.21(0.35-4.23)$ & 0.755 & - & - \\
\hline Caucasian Shepherd & $1.32(0.27-6.37)$ & 0.73 & $1.74(0.36-8.42)$ & 0.489 & - & - \\
\hline Cocker Spaniel & $0.19(0.07-0.53)$ & 0.002 & $0.26(0.09-0.71)$ & 0.009 & - & - \\
\hline Dachshund & $0.68(0.38-1.21)$ & $<0.001$ & $0.16(0.07-0.36)$ & $<0.001$ & $0.25(0.08-0.80)$ & 0.019 \\
\hline Doberman & $0.45(0.16-1.28)$ & 0.137 & $0.45(0.13-1.46)$ & 0.187 & $0.47(0.06-3.46)$ & 0.461 \\
\hline French Bulldog & $2.06(1.11-3.82)$ & 0.021 & $1.99(1.00-3.98)$ & 0.049 & $2.28(0.79-6.55)$ & 0.123 \\
\hline German Shepherd & $0.18(0.09-0.35)$ & $<0.001$ & $0.16(0.07-0.36)$ & $<0.001$ & $0.25(0.08-0.80)$ & 0.019 \\
\hline Golden Retriever & $1.38(0.82-2.33)$ & 0.221 & $1.54(0.88-2.70)$ & 0.127 & $0.89(0.27-2.88)$ & 0.848 \\
\hline Irish Setter & $1.00(0.38-2.65)$ & 0.994 & $1.32(0.50-3.51)$ & 0.568 & - & - \\
\hline Jack Russell Terrier & $1.32(0.27-6.37)$ & 0.73 & $0.86(0.10-7.08)$ & 0.896 & $2.74(0.33-22.46)$ & 0.347 \\
\hline Labrador & $2.50(1.75-3.58)$ & $<0.001$ & $2.72(1.84-4.00)$ & $<0.001$ & $1.85(0.91-3.76)$ & 0.088 \\
\hline Maltese & $2.06(0.63-6.71)$ & 0.231 & $2.72(0.83-8.89)$ & 0.097 & - & - \\
\hline Miniature Poodle & $2.31(0.42-12.66)$ & 0.334 & $1.52(0.17-13.66)$ & 0.707 & $4.80(0.53-43.30)$ & 0.162 \\
\hline Miniature Schnauzer & $0.61(0.27-1.36)$ & 0.232 & $0.69(0.29-1.63)$ & 0.408 & $0.36(0.05-2.63)$ & 0.316 \\
\hline Polish Tatra Sheepdog & $1.98(0.51-7.70)$ & 0.322 & $1.74(0.36-8.42)$ & 0.489 & $2.74(0.33-22.46)$ & 0.347 \\
\hline Pug & $4.63(0.93-23.04)$ & 0.061 & $6.13(1.23-30.48)$ & 0.027 & - & - \\
\hline Saint Bernard & $0.65(0.14-2.90)$ & 0.581 & $0.86(0.19-3.83)$ & 0.853 & - & - \\
\hline Shar-Pei & $6.82(2.89-16.04)$ & $<0.001$ & $0.67(0.08-5.34)$ & 0.71 & $28.18(11.62-68.34)$ & $<0.001$ \\
\hline Siberian Husky & $0.41(0.12-1.36)$ & 0.147 & $0.55(0.16-1.80)$ & 0.323 & - & - \\
\hline Standard Poodle & $0.41(0.09-1.78)$ & 0.238 & $0.55(0.12-2.35)$ & 0.421 & - & - \\
\hline Standard Schnauzer & $0.79(0.30-2.06)$ & 0.635 & $0.62(0.19-2.06)$ & 0.443 & $1.32(0.31-5.60)$ & 0.705 \\
\hline Weimaraner & $2.31(0.57-9.29)$ & 0.236 & $1.01(0.12-8.45)$ & 0.989 & $6.45(1.28-32.31)$ & 0.023 \\
\hline Yorkshire Terrier & $0.11(0.02-0.45)$ & 0.002 & $0.14(0.03-0.59)$ & 0.007 & - & - \\
\hline
\end{tabular}

Table 5 Odds ratios (ORs) and $95 \%$ confidence intervals (Cls) for particular grades of MCTs by tumour location

\begin{tabular}{|c|c|c|c|c|c|c|}
\hline \multirow[t]{3}{*}{ Location } & \multirow{2}{*}{\multicolumn{2}{|c|}{ All MCTs }} & \multicolumn{4}{|l|}{ Kiupel grade } \\
\hline & & & \multicolumn{2}{|l|}{ Low } & \multicolumn{2}{|l|}{ High } \\
\hline & OR $(95 \% \mathrm{Cl})$ & $\mathbf{P}$ & OR $(95 \% \mathrm{Cl})$ & $\mathbf{P}$ & OR $(95 \% \mathrm{CI})$ & $\mathbf{P}$ \\
\hline Anus & $0.11(0.04-0.24)$ & $<0.001$ & $6.99(2.68-18.24)$ & $<0.001$ & $31.72(12.70-79.23)$ & $<0.001$ \\
\hline Axilla & $2.21(1.32-3.71)$ & 0.003 & $1.03(0.48-2.21)$ & 0.925 & $6.30(3.36-11.82)$ & $<0.001$ \\
\hline Head & $0.44(0.32-0.59)$ & $<0.001$ & $0.48(0.34-0.67)$ & $<0.001$ & $0.32(0.16-0.62)$ & 0.001 \\
\hline Inguinal area & $5.46(2.58-11.55)$ & $<0.001$ & $1.88(0.61-5.80)$ & 0.271 & $17.69(7.74-40.40)$ & $<0.001$ \\
\hline Neck & $0.88(0.54-1.42)$ & 0.614 & $0.88(0.52-1.52)$ & 0.667 & $0.87(0.34-2.17)$ & 0.766 \\
\hline Pelvic limb & $0.72(0.56-0.94)$ & 0.015 & $0.62(0.47-0.81)$ & 0.001 & $1.38(0.77-2.49)$ & 0.276 \\
\hline Pelvic limb & $0.72(0.56-0.94)$ & 0.015 & $0.62(0.47-0.81)$ & 0.001 & $1.38(0.77-2.49)$ & 0.276 \\
\hline Perineum & $1.93(0.97-3.81)$ & 0.058 & $1.05(0.40-2.73)$ & 0.92 & $4.83(2.07-11.27)$ & $<0.001$ \\
\hline Scrotum & $12.61(5.55-28.64)$ & $<0.001$ & $6.99(2.68-18.24)$ & $<0.001$ & $31.72(12.70-79.23)$ & $<0.001$ \\
\hline Tail & $0.58(0.3-1.13)$ & 0.112 & $0.77(0.39-1.51)$ & 0.453 & - & - \\
\hline Thoracic limb & $0.84(0.62-1.14)$ & 0.274 & $0.96(0.69-1.34)$ & 0.836 & $0.48(0.23-1.00)$ & 0.05 \\
\hline Torso & $1.59(1.29-1.95)$ & $<0.001$ & $1.74(1.38-2.18)$ & $<0.001$ & $1.17(0.78-1.75)$ & 0.43 \\
\hline
\end{tabular}




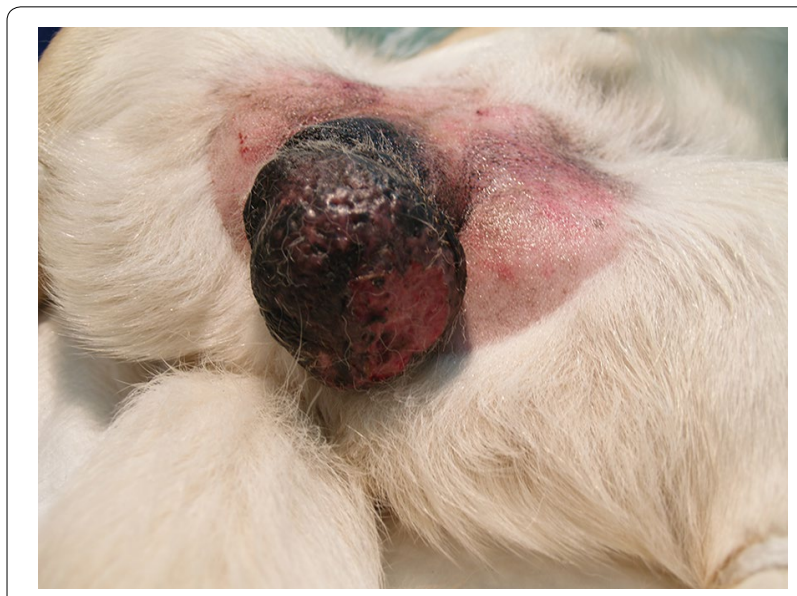

Fig. 1 High-grade MCT in the scrotum of a 9-year-old Labrador

the skin tumour locations. The results also indicated that this area was susceptible to a substantially higher risk of high-grade tumours (OR 31.72, $\mathrm{P}<0.001$ ), although the OR value for low-grade MCTs was also high (OR 12.61, $\mathrm{P}<0.001$ ) (Table 4). Other regions predisposed to the development of MCTs were the inguinal area and axilla (Table 4). As shown in the literature, the inguinal, scrotal, and perianal areas, as well as the mucocutaneous junctions, are tumour locations characterised by a worse prognosis [1, 2, 4, 12, 27]. However, it should be borne in mind that the worse prognosis may be associated with the difficulty of applying an appropriate surgical procedure and incomplete tumour resection $[1,3]$. The present results confirmed the tendency towards the development of high-grade MCTs in the inguinal and axillary regions
(Table 4). As reported by Govier [26], mechanical irritation and chronic inflammation may contribute to the development of this tumour. The inguinal and axillary regions are exposed to mechanical irritation, which may contribute to the worse course of the disease. The statistical analysis revealed an increased risk of the development of MCTs on the torso and confirmed this region's predilection for the occurrence of low-grade MCTs (Table 4).

Mast cell tumours can develop in dogs at all ages, but most cases are diagnosed between 7.5 and 9 years of age $[2,4,12,40]$. The present study confirmed a higher MCT risk in older dogs aged 4-6 (OR 7.23, $\mathrm{P}<0.001)$ and $7-10$ years $($ OR $7.49, \mathrm{P}<0.001)$ than in the younger group (Table 5). Shoop et al. [20] found a 41-fold higher risk of MCT development in 10-year-old dogs compared with that in dogs aged 2 years. In turn, Villamil et al. [21] observed an increased MCT incidence in dogs older than 7 years. The statistical analyses presented in this study revealed interesting correlations between a dog's age and the malignancy grade of MCTs. The comparison with the youngest dogs revealed that the risk of high-grade MCT development increased with age, reaching a maximum value in the oldest group of dogs, aged 11-16 years. In the case of low-grade tumours, the risk was higher in younger dogs, aged 4-6, and declined in the oldest group, aged over 11 years (Table 5). In previous epidemiological studies, no correlations were demonstrated between age and the risk of various-grade MCTs. An investigation conducted by Mochizuki et al. [25] showed an increased risk of mast cell malignancies, mainly in non-castrated males. The results of the present statistical analyses based on the dog's size revealed a higher risk of low- and high-grade MCTs in medium-sized breeds than in small

Table 6 Odds ratios (ORs) and 95\% confidence intervals (Cls) for particular grades of MCTs by age, size and sex

\begin{tabular}{|c|c|c|c|c|c|c|}
\hline \multirow[t]{3}{*}{ Variable } & \multirow{2}{*}{\multicolumn{2}{|c|}{ All MCTs }} & \multicolumn{4}{|l|}{ Kiupel grade } \\
\hline & & & \multicolumn{2}{|l|}{ Low } & \multicolumn{2}{|l|}{ High } \\
\hline & OR $(95 \% \mathrm{Cl})$ & $\mathbf{P}$ & OR $(95 \% \mathrm{Cl})$ & $\mathbf{P}$ & OR $(95 \% \mathrm{Cl})$ & $\mathbf{P}$ \\
\hline \multicolumn{7}{|l|}{ Sex } \\
\hline Male & 1 (base) & - & 1 (base) & - & 1 (base) & - \\
\hline Female & $1.38(1.14-1.69)$ & 0.001 & $1.43(1.14-1.78)$ & 0.001 & $1.26(0.87-1.83)$ & 0.217 \\
\hline \multicolumn{7}{|l|}{ Age (years) } \\
\hline $0-3$ & 1 (base) & - & 1 (base) & - & 1 (base) & - \\
\hline $4-6$ & $7.23(4.16-12.55)$ & $<0.001$ & $8.54(4.53-16.10)$ & $<0.001$ & $3.63(1.21-10.87)$ & 0.021 \\
\hline $7-10$ & $7.49(4.39-12.77)$ & $<0.001$ & $8.18(4.41-15.18)$ & $<0.001$ & $5.57(2.00-15.52)$ & 0.001 \\
\hline $11-16$ & $4.87(2.77-8.56)$ & $<0.001$ & $3.17(1.61-6.24)$ & 0.001 & $9.55(3.41-26.77)$ & $<0.001$ \\
\hline \multicolumn{7}{|l|}{ Size } \\
\hline Small & 1 (base) & - & 1 (base) & - & 1 (base) & - \\
\hline Medium & $2.96(2.18-4.01)$ & $<0.001$ & $3.47(2.45-4.92)$ & $<0.001$ & $1.71(0.96-3.03)$ & 0.066 \\
\hline Large & $0.84(0.59-1.21)$ & 0.366 & $0.90(0.59-1.36)$ & 0.626 & $0.71(0.36-1.38)$ & 0.321 \\
\hline
\end{tabular}


breeds. No such correlation was found for large breeds (Table 5). In contrast, White et al. [23] reported slightly different results, i.e., a several-fold higher risk of MCT development in large and giant breeds than in small ones; however, that analysis was based on body weight rather than height at the withers.

\section{Conclusions}

This study demonstrated relationships between Kiupel grading system and phenotypic traits, age and location of canine MCTs confirming the complex biological nature of this tumour. Retrospective studies conducted in large animal populations present a valuable contribution to knowledge about the clinical nature of MCTs. Data obtained in the present study can be used for the prediction of to determine the impact of various risk factors in breeds that are predisposed to the development of MCTs.

\section{Additional file}

Additional file 1. Photomicrographs of MCT. a: Microscopic Image of High-Grade MCT. Note mitotic figure (arrow) and karyomegaly (arrow head). Haematoxylin and eosin. b: Microscopic Image of Low-Grade MCT. Note round to ovoid nuclei with scattered chromatin. Haematoxylin and eosin.

\section{Abbreviations}

Cl: confidence interval; MCTs: mast cell tumours; OR: odds ratio.

\begin{abstract}
Authors' contributions
AS designed the study, performed research and interpretation of the results, drafted the manuscript. BS and RD participated in statistical analysis. WL and AJ participated in histopathological analysis. DB collected samples and data on breed, age and sex of dogs. All authors read and approved the final manuscript.
\end{abstract}

\section{Author details \\ ${ }^{1}$ Sub-Department of Pathomorphology and Forensic Veterinary Medicine, Department and Clinic of Internal Medicine, Faculty of Veterinary Medi- cine, University of Life Science Lublin, Akademicka 13 St., 20-950 Lublin, Poland. ${ }^{2}$ Department of Biological Bases of Animal Production, Faculty of Animal Breeding and Biology, University of Life Science, Akademicka 13 St., 20-950 Lublin, Poland. ${ }^{3}$ Department of Pathology, National Veterinary Research Institute, Al. Partyzantów 57 St., 24-100 Pulawy, Poland. ${ }^{4}$ Depart- ment of Anatomy and Pathology, University Centre of Veterinary Medicine of Jagiellonian University and University of Agriculture, Mickiewicza 21 St., 31-120 Kraków, Poland. ${ }^{5}$ Department and Clinic of Animal Reproduction, Faculty of Veterinary Medicine, University of Life Sciences, Akademicka 13 St., 20-950 Lublin, Poland.}

\section{Acknowledgements}

Not applicable.

\section{Competing interests}

The authors declare that they have no competing interests.

\section{Availability of data and materials}

The datasets used and analysed during the current study are available from the corresponding author on reasonable request.

\section{Ethics approval and consent to participate}

This study did not require official or institutional ethical approval as it was not experimental.

\section{Funding}

This study was performed by internal funding.

\section{Publisher's Note}

Springer Nature remains neutral with regard to jurisdictional claims in published maps and institutional affiliations.

Received: 8 February 2018 Accepted: 28 October 2018

Published online: 03 November 2018

\section{References}

1. Blackwood L, Murphy S, Buracco P, De Vos JP, De Fornel-Thibaud P, Hirschberger J, et al. European consensus document on mast cell tumours in dogs and cats. Vet Comp Oncol. 2012;10:e1-29.

2. Misdorp W. Mast cells and canine mast cell tumours. A review. Vet $Q$. 2004:26:156-69.

3. Murphy S, Sparkes AH, Smith KC, Blunden AS, Brearley M. Relationships between the histological grade of cutaneous mast cell tumours in dogs, their survival and the efficacy of surgical resection. Vet Rec. 2004; 154:743-6.

4. Welle MM, Bley CR, Howard J, Rüfenacht S. Canine mast cell tumours: a review of the pathogenesis, clinical features, pathology and treatment. Vet Dermatol. 2008;19:321-39.

5. Berlato D, Stewart J, Newton R, Maglennon GA, Monti P, Flindall A, et al. Evaluation of minichromosome maintenance protein 7 as a prognostic marker in canine cutaneous mast cell tumours. Vet Comp Oncol. 2012;10:135-42.

6. Froberg GK, Lindberg R, Ritter M, Nordlind K. Expression of serotonin and its 5-HT1A receptor in canine cutaneous mast cell tumours. J Comp Pathol. 2009;141:89-97.

7. Poggiani SSC, Terra EM, Neto RT, Costa MT, Amorim RL. Canine cutaneous mast cell tumor: biologic behavior and its correlation with prognostic indicators. Open J Vet Med. 2012;2:255-61.

8. Romansik EM, Reilly CM, Kass PH, Moore PF, London CA. Mitotic index is predictive for survival for canine cutaneous mast cell tumors. Vet Pathol. 2007:44:335-41.

9. Wu H, Hayashi T, Inoue M. Immunohistochemical expression of Mdm2 and p53 in canine cutaneous mast cell tumours. J Vet Med A Physiol Pathol Clin Med. 2006;53:65-8.

10. Zemke D, Yamini B, Yuzbasiyan-Gurkan V. Mutations in the juxtamembrane domain of C-KIT are associated with higher grade mast cell tumors in dogs. Vet Pathol. 2002;39:529-35.

11. Brønden LB, Eriksen T, Kristensen AT. Mast cell tumours and other skin neoplasia in Danish dogs - data from the Danish veterinary cancer registry. Acta Vet Scand. 2010;52:6.

12. Dobson JM, Scase TJ. Advances in the diagnosis and management of cutaneous mast cell tumours in dogs. J Small Anim Pract. 2007:48:424-31.

13. Patnaik AK, Ehler WJ, MacEwen EG. Canine cutaneous mast cell tumor: morphologic grading and survival time in 83 dogs. Vet Pathol. 1984;21:469-74.

14. Kiupel M, Webster JD, Bailey KL, Best S, DeLay J, Detrisac CJ, et al. Proposal of a 2-tier histologic grading system for canine cutaneous mast cell tumors to more accurately predict biological behavior. Vet Pathol. 2011;48:147-55.

15. Artuković $B$, Medven L, Hohšteter M, Šoštarić-Zuckermann I-C, Kurilj AG, Beck A, et al. Prevalence of cutaneous mast cell sarcoma in dogs in Croatia. Vet Arhiv. 2014;84:601-14.

16. Grüntzig K, Graf R, Hassig M, Welle M, Meier D, Lott G, et al. The Swiss Canine Cancer Registry: a retrospective study on the occurrence of tumours in dogs in Switzerland from 1955 to 2008. J Comp Pathol. 2015;152:161-71.

17. Grüntzig K, Graf R, Boo G, Guscetti F, Hässig M, Axhausen KW, et al. Swiss Canine Cancer Registry 1955-2008: occurrence of the most common tumour diagnoses and influence of age, breed, body size, 
sex and neutering status on tumour development. J Comp Pathol. 2016;155:156-70.

18. Dobson JM, Samuel S, Milstein H, Rogers K, Wood JL. Canine neoplasia in the UK: estimates of incidence rates from a population of insured dogs. J Small Anim Pract. 2002:43:240-6.

19. Leidinger EF, Freeman K, Kirtz G, Hooijberg EH, Sick K. Breed related odds ratio and anatomic distribution of canine mast cell tumours in Austria. Retrospective study of cases in the years 2000-2010. Tierarztl Prax Ausg K Kleintiere Heimtiere. 2014:42:367-73.

20. Shoop SJW, Marlow S, Church DB, English K, McGreevy PD, Stell AJ, et al. Prevalence and risk factors for mast cell tumours in dogs in England. Canine Genet Epidemiol. 2015;2:1.

21. Villamil JA, Henry CJ, Bryan JN, Ellersieck M, Schultz L, Tyler JW, et al. Identification of the most common cutaneous neoplasms in dogs and evaluation of breed and age distributions for selected neoplasms. J Am Vet Med Assoc. 2011;239:960-5.

22. Warland J, Dobson J. Breed predispositions in canine mast cell tumour: a single centre experience in the United Kingdom. Vet J. 2013;197:496-8.

23. White CR, Hohenhaus AE, Kelsey J, Procter-Gray E. Cutaneous MCTs: associations with spay/neuter status, breed, body size, and phylogenetic cluster. J Am Anim Hosp Assoc. 2011;47:210-6.

24. Zink MC, Farhoody P, Elser SE, Ruffini LD, Gibbons TA, Rieger RH. Evaluation of the risk and age of onset of cancer and behavioral disorders in gonadectomised Vizslas. J Am Vet Med Assoc. 2014;244:309-19.

25. Mochizuki H, Motsinger-Reif A, Bettini C, Moroff S, Breen M. Association of breed and histopathological grade in canine mast cell tumours. Vet Comp Oncol. 2017;15:829-39.

26. Govier SM. Principles of treatment for mast cell tumors. Clin Tech Small Anim Pract. 2003;18:103-6.

27. Sfiligoi G, Rassnick KM, Scarlett JM, Northrup NC, Gieger TL. Outcome of dogs with mast cell tumors in the inguinal or perineal region versus other cutaneous locations: 124 cases (1990-2001). J Am Vet Med Assoc. 2005;226:1368-74.

28. Hendrick MJ. Histological classification of mesenchymal tumors of skin and soft tissues of domestic animals. 2nd ed. Washington, D.C: Armed Forces Institute of Pathology; 1998.
29. Pionnier-Capitan M, Bemilli C, Bodu P, Célérier G, Ferrié J-G, Fosse P, et al. New evidence for Upper Palaeolithic small domestic dogs in SouthWestern Europe. J Archaeol Sci. 2011;38:2123-40.

30. Finnie JW, Bostock DE. Skin neoplasia in dogs. Aust Vet J. 1979;55:602-4.

31. Peters JA. Canine mastocytoma: excess risk as related to ancestry. J Natl Cancer Inst. 1969;42:435-43.

32. Dobson JM. Breed-predispositions to cancer in pedigree dogs. ISRN Vet Sci. 2013. https://doi.org/10.1155/2013/941275.

33. Miller DM. The occurrence of mast cell tumors in young Shar-Peis. J Vet Diagn Invest. 1995;7:360-3.

34. Thamm DH, Vail DM. Mast cell tumors. In: Withrow SJ, Mac Ewen EG, editors. Small animal clinical oncology. Philadelphia: W. B. Saunders; 2001. p. 261-82.

35. Wakshlag JJ, Rassnick KM, Malone EK, Struble AM, Vachhani P, Trump $\mathrm{DL}$, et al. Cross-sectional study to investigate the association between vitamin $\mathrm{D}$ status and cutaneous mast cell tumours in Labrador retrievers. Br J Nutr. 2011;106(Suppl 1):S60-3.

36. Bostock DE. Neoplasms of the skin and subcutaneous tissues in dogs and cats. Br Vet J. 1986;142:1-19.

37. McNiel EA, Prink AL, O'Brien TD. Evaluation of risk and clinical outcome of mast cell tumours in pug dogs. Vet Comp Oncol. 2006;4:2-8.

38. Śmiech A, Ślaska B, Surdyka M, Grzybowska-Szatkowska L, Łopuszyński W, Różańska D. Identification of additional mitochondrial DNA mutations in canine mast cell tumours. Acta Vet Scand. 2016;58:28.

39. Kiupel M, Webster JD, Miller RA, Kaneene JB. Impact of tumour depth, tumour location and multiple synchronous masses on the prognosis of canine cutaneous mast cell tumours. J Vet Med A Physiol Pathol Clin Med. 2005;52:280-6.

40. O'Connell K, Thomson M. Evaluation of prognostic indicators in dogs with multiple, simultaneously occurring cutaneous mast cell tumours: 63 cases. Vet Comp Oncol. 2013;11:51-62.
Ready to submit your research? Choose BMC and benefit from:

- fast, convenient online submission

- thorough peer review by experienced researchers in your field

- rapid publication on acceptance

- support for research data, including large and complex data types

- gold Open Access which fosters wider collaboration and increased citations

- maximum visibility for your research: over $100 \mathrm{M}$ website views per year

At BMC, research is always in progress.

Learn more biomedcentral.com/submissions 